\title{
Improved methods for measuring forest landscape structure: LiDAR complements field-based habitat assessment
}

\author{
Florian Zellweger • Felix Morsdorf • Ross S. Purves • Veronika Braunisch • \\ Kurt Bollmann
}

Received: 8 June 2013/Accepted: 21 November 2013/Published online: 5 December 2013

(C) Springer Science+Business Media Dordrecht 2013

\begin{abstract}
Conservation and monitoring of forest biodiversity requires reliable information about forest structure and composition at multiple spatial scales. However, detailed data about forest habitat characteristics across large areas are often incomplete due to difficulties associated with field sampling methods. To overcome this limitation we employed a nationally available light detection and ranging (LiDAR) remote sensing dataset to develop variables describing forest landscape structure across a large environmental gradient in Switzerland. Using a model species indicative of structurally rich mountain forests (hazel grouse Bonasa bonasia), we tested the potential of such variables to predict species occurrence and evaluated the additional benefit of LiDAR data when used in combination with traditional, sample plot-based field variables. We calibrated boosted regression trees (BRT) models for both variable sets separately and in combination, and compared the models' accuracies. While both field-based and LiDAR models performed well, combining the two data sources improved the accuracy of the species' habitat model. The variables
\end{abstract}

Electronic supplementary material The online version of this article (doi:10.1007/s10531-013-0600-7) contains supplementary material, which is available to authorized users.

F. Zellweger $(\bowtie) \cdot$ K. Bollmann

Swiss Federal Institute for Forest, Snow and Landscape Research WSL, Zürcherstrasse 111, 8903

Birmensdorf, Switzerland

e-mail: florian.zellweger@wsl.ch

F. Morsdorf

Remote Sensing Laboratories, Department of Geography, University of Zürich, Zürich, Switzerland

R. S. Purves

Department of Geography, University of Zürich, Zürich, Switzerland

V. Braunisch

Conservation Biology, Institute of Ecology and Evolution, University of Bern, Baltzerstrasse 6, 3012

Bern, Switzerland

V. Braunisch

Forest Research Institute of Baden-Württemberg, Wonnhaldestrasse 4, 79100 Freiburg, Germany 
retained from the two datasets held different types of information: field variables mostly quantified food resources and cover in the field and shrub layer, LiDAR variables characterized heterogeneity of vegetation structure which correlated with field variables describing the understory and ground vegetation. When combined with data on forest vegetation composition from field surveys, LiDAR provides valuable complementary information for encompassing species niches more comprehensively. Thus, LiDAR bridges the gap between precise, locally restricted field-data and coarse digital land cover information by reliably identifying habitat structure and quality across large areas.

Keywords Airborne laser scanning - Bonasa bonasia $\cdot$ Habitat model · Mountain forest $\cdot$ Remote sensing $\cdot$ Species conservation

\section{Introduction}

Species richness in forest ecosystems largely depends on forest structure and composition, because these two attributes are major determinants of potential niches provided by a forest plant community (Noss 1990; Franklin et al. 2002). Forest management continuously alters the structure and composition of most European forest ecosystems, reflected in a general reduction in stand age through reduced rotation lengths, and more homogeneous tree compositions through the promotion of commercially preferred tree species (Larsson 2001). Since measures for conserving and improving forest biodiversity in commercially used forests often aim to enhance or restore structural complexity, quantifying forest structural characteristics, and linking them to forest biodiversity, is a prime task in conservation research.

Traditional conservation studies typically rely on forest vegetation data gained in plotbased field assessments across limited spatial extents, restricting the generality of analysis. To overcome these limitations, the use of remote sensing information in biological studies has become increasingly important (Turner et al. 2003). Light detection and ranging (LiDAR) is an active remote sensing technique that can quantify the three-dimensional structure of forests and other ecosystems over large areas at a high level of detail. This makes it a promising tool for ecosystem studies (Lefsky et al. 2002), such as wildlife habitat analysis (Bradbury et al. 2005; Vierling et al. 2008). Structural diversity in forest stands can be directly quantified with LiDAR-based vegetation profile metrics of the vertical complexity of canopy elements (Goetz et al. 2010, 2007). LiDAR-derived metrics of vegetation height, density or volume as well as variables based on single tree crowns have been found to be good predictors of species distributions and habitat suitability (Hill et al. 2004; Swatantran et al. 2012; Seavy et al. 2009) and useful indicators of avian species diversity (Clawges et al. 2008; Müller et al. 2009b). Most studies using airborne-LiDAR to investigate animal-habitat relationships calibrated forest structural habitat variables on plots with dimensions ranging from 10 s to 100 s of meters, and restricted the analysis to small regions, mainly due to limited LiDAR data availability (Vierling et al. 2008). With increasing effort to acquire airborne-LiDAR data at the national or state level the question arises as to how LiDAR can be applied to quantify habitat structure at the landscape level across larger regions. Apart from incorporating insights from local- or forest stand-scale LiDAR analysis, this requires the development of novel indicator variables whose ecological relevance may only emerge from landscape-scale or between-stand analysis. Biodiversity relevant structural indicators at the landscape scale include metrics of heterogeneity, structural complexity, connectivity, ecotones, gaps or structural patterns caused by local disturbances (e.g. windthrow, snow movements or bark beetle infestations) 
(Lindenmayer et al. 2000). Since these indicators are difficult to assess using ground surveys, alternative methods and metrics utilizing LiDAR may provide a reliable route to quantifying such forest landscape characteristics. Furthermore, few studies explicitly evaluating the added value of LiDAR-based habitat models compared to conventional approaches have been carried out (e.g. Müller et al. 2009b). The advent of national LiDAR datasets is an opportunity to explore these potential benefits of large-scale habitat surveys across broad spatial extents.

Recently, multifunctional forest management in Central Europe has started to recognize the role of natural processes (e.g. natural regeneration) and dynamics after disturbances (e.g. severe windstorms) as drivers of structural heterogeneity (Attiwill 1994; Schönenberger 2001). Simultaneously, the increased rate of abandonment of Alpine farms and pastures in Central Europe has resulted in an increase of forest area characterized by ingrowth of natural regeneration and pioneer trees and shrubs (Gehrig-Fasel et al. 2007). These changes shape the structure and composition of mountain forests and are thus of significance for a wide variety of conservation-relevant species (Stöcklin et al. 2007). Methods to quantify these changes are required, in order to support planning efforts to conserve biodiversity in mountain forests in general. LiDAR may meet these requirements because it provides precise information about vegetation heights and the distribution of vertical canopy elements, thus allowing for a direct characterization of three-dimensional habitat structure. Yet, LiDAR derived variables that adequately reflect the relevant forest structures and their diversity need to be identified and their ecological relevance verified, e.g. by evaluating their performance in predicting the occurrence of species with specific, well-known structural requirements.

Hazel grouse (Bonasa bonasia), a forest bird highly sensitive to forest structure and composition (Bergmann et al. 1996), is one potential model species which can be used to develop and evaluate such methods. This threatened sedentary forest bird species occupies territories ranging from 20 to 40 ha (Swenson 1991) and inhabits early succession stages with pioneer plant communities as well as small regeneration areas embedded in old-growth forests (Bergmann et al. 1996). Its present distribution in Central Europe is largely restricted to the Alpine region (Klaus et al. 2003), where the required forest structural heterogeneity is still preserved by small-scale changes in site conditions through local disturbances (e.g. windthrow, snow movements, snow breakage, insects, diseases) and forest management practices in favor of resource trees and shrubs (Schäublin and Bollmann 2011).

This study thus aims to qualitatively and quantitatively evaluate the value of nationally available LiDAR data for large-scale habitat assessments across a broad range of Central European mountain forest conditions, using hazel grouse as a model species indicative of structurally complex forest ecosystems. We compare model fit and predictive performance of models based on (a) traditional, sample plot-based field data of forest structure and composition, (b) LiDAR-based variables of forest landscape structure considering both, the vertical and horizontal heterogeneity of canopy elements, and (c) a combined model taking advantage of both. We identify species-relevant, complementary predictors from both datasets and derive threshold values to support forest management in terms of habitat improvement measures.

\section{Materials and methods}

Study area

The study area covers $21,620 \mathrm{~km}^{2}$ and includes three biogeographic regions within Switzerland: the Swiss Jura, the Northern Prealps and the Eastern Central Alps (Fig. 1a). 
The biogeographical classification is based on distribution patterns of flora and fauna (Gonseth et al. 2001) and the three regions represent an ecological stratification with respect to mountain forest ecosystems. In the Swiss Jura, elevations do not reach the tree line and forests form semi-continuous habitats interrupted by pasture grasslands. In the Northern Prealps, subalpine forests have their upper limit at about 1,800 $\mathrm{m}$ above sea level (m.a.s.l.) and mountain tops with elevations of up to over 3,000 m.a.s.l. occasionally punctuate the potential natural forest cover. The Eastern Central Alps are characterized by high relief over short distances, with mountains reaching elevations of up to 4,000 m.a.s.l. The forests in this region occur in belts around mountain ranges, and the upper tree line lies at around 2,300 m.a.s.l. The natural tree species composition varies along the altitudinal gradient, with European beech (Fagus sylvatica) and silver fir (Abies alba) dominating the montane altitudinal belt, while Norway spruce (Picea abies) predominates in the subalpine belt. The climatic conditions in the Jura and Northern Prealps are mostly oceanic; while in the Eastern Central Alps a continental climate prevails, which is reflected by a larger proportion of larch (Larix decidua) and Swiss stone pine (Pinus cembra).

\section{Species data and study design}

We applied a species presence/absence approach for a comparison of used versus unused habitat (Jones 2001). The reference grid of the Swiss coordinate system with a cell size of $1 \mathrm{~km}^{2}$ was used to delineate pairs of cells with species presence and absence (Fig. 1b). Our intention was to analyze landscapes dominated by forests. Thus we restricted the selection of presence/absence cells to cells with more than $50 \%$ forest cover, as delineated by the digital mapping product Vector25 (Swisstopo 2012).

Species presence data were taken from the database of the Swiss Ornithological Institute and the grouse database of the Swiss Federal Research Institute for Forest, Snow and Landscape Research (WSL), both of which include multi-year species evidence at a resolution of $1 \mathrm{~km}^{2}$. The data originates from the Swiss national bird monitoring program and consists of reported species evidences from a dense and area-wide network of species specialists and qualified ornithologists who regularly report direct (e.g. sightings, territory calls) and indirect (e.g. feathers and/or droppings) evidences of species presence. All reports were validated by experts from the Swiss Ornithological Institute and the WSL, and allocated to the respective $\mathrm{km}^{2}$ cell of the Swiss coordinate system. To account for multiyear species prevalence we only considered cells with at least three years of observation between 2006 and 2010. Presence cells were chosen to represent the altitudinal gradient and the distribution range of hazel grouse in each study region. The $1-\mathrm{km}^{2}$ resolution of our species data approximates to three times the home range size of a single hazel grouse pair, thus taking into account the territory itself and its immediate surroundings. This allowed us to investigate on the relationship between structural variables of forest landscapes and species occurrence. The broad spatial coverage, representing the wide ecological range of Central European mountain forest conditions and most of the species environmental niche profile, is expected to compensate for the lack of smaller-scale occupancy data and to improve the generality of the results, as demonstrated by Braunisch and Suchant (2010).

Pseudo-absence cells (from now on referred to as absence cells) were defined as cells with no reported species evidence between 2000 and 2010. Since we assumed that absence cells are locations which could potentially be used by the species but are unused due to suboptimal habitat characteristics, pairs of presence and absence cells were located in the same valley within dispersal distance, in our case set to a maximum of $4 \mathrm{~km}$. We applied a paired multi-criteria model to allocate the absence cells. Starting from a presence cell 
Fig. 1 Study area and sampling design. The study area

(a) consists of three biogeographic mountain regions in Switzerland: Jura (1), Northern Prealps (2) and Central Eastern Alps (3). Dots indicate hazel grouse presence (white) and absence (black) cells. The map (Swisstopo 2012) extract in (b) shows the sampling design with the $\mathrm{km}^{2}$ reference grid and a presence (white frame) and an absence (black frame) sampling cell including 16 field sampling plots. Sampling plots (c) were divided into quarters of which the center points define the corners of the nested square. The nested square was again divided into quarters of which number 1 and 3 were used to sample the ground vegetation

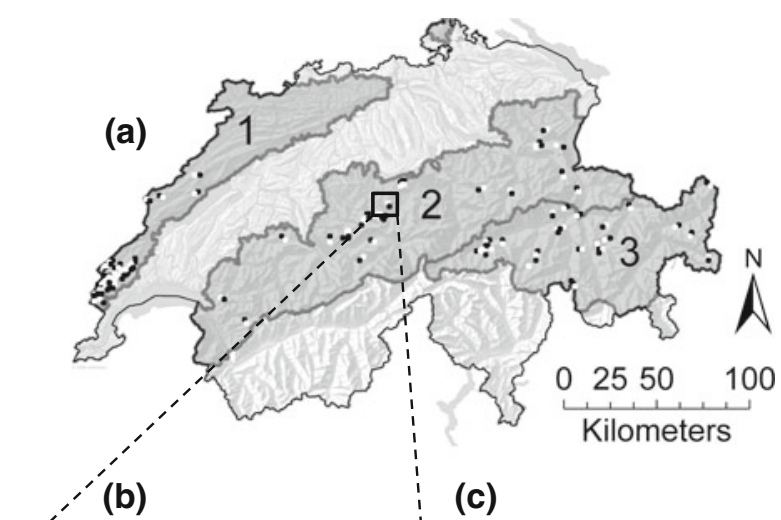

Field sampling plot $30 \times 30 \mathrm{~m}$

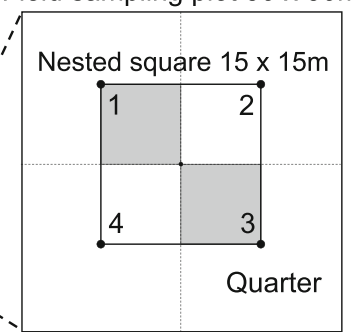

(Fig. 1b), a first order square of all adjacent cells $(N=8)$ was designated, followed by a second $(N=16)$, third $(N=24)$ and fourth $(N=32)$ order square. Considering the two criteria mentioned above, an absence cell was selected randomly from the second order square. In cases where the two criteria were not met, the absence cell was allocated in the third or fourth order square. $80 \%$ of the absence cells could be placed in the second order square.

For the analyses, we used 161 cells (91 presence and 70 absence), evenly split between the three study regions. The uneven number of presence/absence cells was due to two reasons: firstly, observations of hazel grouse in absence cells during the field survey required a reclassification of some absence cells and second, inaccessibility during the field survey or lack of availability of LiDAR data led to the exclusion of some absence cells.

Field-based habitat assessment

All field measurements were carried out from June to September 2011. To obtain representative data of the habitat characteristics for each presence and absence cell we established 16 regularly distributed sampling plots measuring $30 \times 30 \mathrm{~m}$ in each cell (Fig. 1c). Within each plot we delineated a nested square $(15 \times 15 \mathrm{~m})$, which was subdivided into four quarters measuring $7.5 \times 7.5 \mathrm{~m}$. Plot centers were located with a GPS device and marked with a ranging pole. The plot outline $(30 \times 30 \mathrm{~m})$ as well as the nested square were measured with a measurement tape and the corners marked with ranging poles. All plots were aligned parallel to the mean slope with the top left ground vegetation quarter being number one.

Field surveys were restricted to plots that were covered with forest as defined by the Swiss National Forest Inventory (NFI 3, Keller 2005). It involves a set of decision criteria 
defining forest: namely, degree of cover (i.e. $>20 \%$ ), the spatial extent (i.e. width of interpreted area $>25 \mathrm{~m}$ ) and the minimal stand height (i.e. $>3 \mathrm{~m}$ ). We investigated a set of 21 variables that have previously been shown to reflect hazel grouse habitat requirements in terms of stand characteristics, stand composition, ground vegetation, resources or functional trees and ecotones (Bergmann et al. 1996; Mathys et al. 2006; Schäublin and Bollmann 2011). For reasons of precision, the different variables were assessed for different reference areas (plot, nested square, nested quarter). A detailed description of the variables and the reference area is provided in Online Resource 1.

Stand characteristics were assessed for the whole plot area. They included canopy and shrub cover, as proxies for thermal and light conditions in the lower forest layers and cover from predators. Stand composition variables provided information about cover as well as the availability of feeding trees and shrubs. Ground vegetation cover, composition and distribution were sampled in more detail in two of the nested-square quarters (Fig. 1c) because hazel grouse-a ground-nesting bird-strongly depends on small-scale availability and configuration of visual cover and food resources. Tall and fruiting rowans (Sorbus aucuparia) are an important food resource (Schäublin and Bollmann 2011) and were sampled within the nested square. Both the number of fruiting rowans as well as the total number of rowans taller than $3 \mathrm{~m}$ was recorded, so as to overcome potential variation derived from regional and seasonal differences in the fruiting intensity of this plant species. Ecotones were classified into the following six categories and recorded if they intersected with the plot area. Inner forest edges (1) were defined as transitions to gaps or clearings with a minimum area of $30 \times 30 \mathrm{~m}$. Outer forest edges (2) include transitions to open land. Further, ecotones between successional stages (3) along water bodies (4) and along forest roads (5) were recorded. Transitions to other ecotones (6) included transitions to erosion gullies or steep hillsides.

\section{LiDAR-based habitat assessment}

We developed a set of LiDAR-based habitat variables describing horizontal and vertical forest structural attributes across the entire area of presence and absence cells. Horizontal structures included landscape-level features such as the heterogeneity and spatial arrangement of different canopy height classes. Variables quantifying vertical structures related to the vertical complexity of canopy elements and reflect features such as multistoried stand profiles, which have been shown to be preferred by hazel grouse (Mathys et al. 2006).

Variables were constructed using a nationwide dataset of discrete, first and last return LiDAR provided by the Swiss Federal Department of Topography. The data were acquired between the years 2000-2007 in different seasons and with a nominal footprint size in the range of small-footprint laser scanning (i.e. several decimeters). Although LiDAR data with an identical sampling period to field measurements would be preferable, nationally available data are collected for a variety of purposes over a longer time span, and we consider the advantages of the broad coverage outweigh the disadvantages. Furthermore, the seasonal effect is expected to be reduced because the forests in the study area are dominated by evergreen coniferous tree species. The mean point density in the studied areas was $1.4 \mathrm{~m}^{-2}$. The reported standard deviation (SD) of height accuracy was $0.5 \mathrm{~m}$ in open areas and $1.5 \mathrm{~m}$ in forested areas. Data were delivered in the form of classified point clouds for both terrain (DTM) and surface (DOM) models (DTM-AV, DOM-AV ${ }^{\odot} 2011$ Swisstopo (5704 000 000); Artuso et al. 2003). 
MATLAB R2011a (Mathworks, Natick, Massachusetts, USA) routines as applied in earlier studies (e.g. Morsdorf et al. 2010) were used to derive the terrain corrected vegetation heights within every $1 \mathrm{~km}^{2}$ presence and absence cell (processing details provided in Online Resource 2). A moving window was applied to interpolate the terrain corrected vegetation heights to form a continuous canopy height model (CHM) with a $4 \times 4 \mathrm{~m}$ horizontal pixel size (Fig. 2), which corresponds to an average tree crown projection in spruce ( $P$. abies) dominated mountain forests. To allow for further analysis in FRAGSTATS - an open source software designed for the analysis of spatial patterns of landscape structure (McGarigal et al. 2002) — the CHM was classified into four height classes as indicated in Fig. 2. The choice of height thresholds, particularly the $5 \mathrm{~m}$ value delimiting the lowest vegetation class, is a compromise between habitat related considerations such as the structural richness of lower forest strata and the reduced number of return pulses available in the lower strata due to the shading effect of higher layers (Goodwin et al. 2007).

FRAGSTATS computes metrics at patch, class and landscape levels (McGarigal et al. 2002). We used class- and landscape-level metrics for further analysis. To identify metrics that reflect relevant forest structural elements of hazel grouse habitat, a preselected set of metrics with potential species relevance was tested on a subsample of the data. The retained metrics are summarized in Online Resource 3 and encompass structural elements such as the diversity and evenness among lower height class areas and the size, form and level of aggregation of class patches across the landscape. Ecotones were represented by metrics quantifying the number of edges between height classes, such as canopy height heterogeneity $(\mathrm{CHH})$, which corresponds to the total border length $(\mathrm{m})$ between the three vegetation $\mathrm{CHM}$ class patches.

To describe species-relevant structural attributes such as multi-storied profiles or the occurrence of understory shrub vegetation we analyzed the vertical clustering of forest vegetation using height and density-related percentiles of vegetation heights (point cloud statistics, Fig. 3). In order to include sufficient vegetation points (laser echoes) for deriving the percentiles, we created a multi-layer raster on a $10 \times 10 \mathrm{~m}$ grid, with the vegetation heights above each pixel being subdivided into ten layers, indicating the percentiles, where the 10th percentile describes vegetation close to the ground and the 100th percentile the upper canopy. Height related percentiles indicate the height (in meters), below which a relative number of points occur. For example, if the 20th height percentile is at $6 \mathrm{~m}$, this means that the lowest $20 \%$ of the vegetation points occur below $6 \mathrm{~m}$. Density-related percentiles, on the other hand, reflect the relative proportion of points occurring within a fixed height class. For example, if the highest vegetation point in a forest is $37 \mathrm{~m}$ (see Fig. 3), the density percentiles are the relative proportions of points that fall within each fixed height class measuring $3.7 \mathrm{~m}$ in height. For every presence and absence cell, minimum, maximum, mean and SD of all height and density related percentiles were calculated over all $10 \mathrm{~m}$ grid cells for each layer. In addition, we computed penetration ratios of laser returns at different height levels (in percent, sum of laser returns $\leq$ height level, divided by sum of all laser returns), which are indicators of the light and temperature conditions in the lower stratum of forests (Müller and Brandl 2009). A more detailed description of the LiDAR data processing and variable definition is provided in Online Resource 2 and 3.

Statistical/machine learning analysis

Boosted regression trees (BRTs) were used to model hazel grouse presence as a function of field and LiDAR derived predictor variables. BRTs are an advanced machine learning 

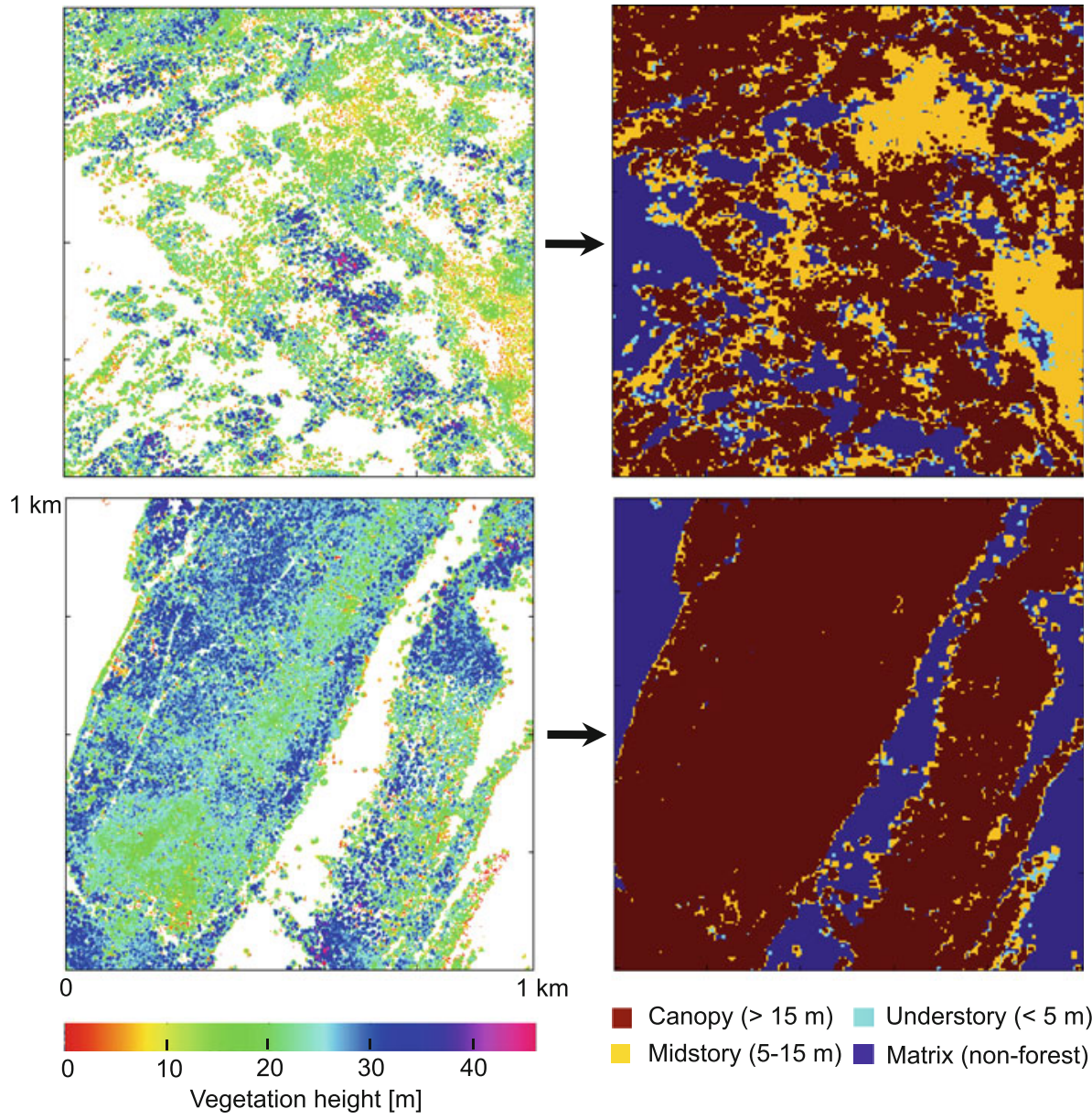

Canopy $(>15 \mathrm{~m}) \square$ Understory $(<5 \mathrm{~m})$

Midstory (5-15 m) Matrix (non-forest)

Fig. 2 Orthogonal projection of terrain corrected vegetation heights (left) and classified canopy height models (CHM, 4-m resolution) (right) for a $1 \mathrm{~km}^{2}$ presence (top) and absence cell (bottom)

based regression modeling technique that can handle any variable type (e.g. numeric, binary, categorical), are insensitive to outliers and automatically model typical ecological features such as nonlinearities and interactions (Friedman 2002; Elith et al. 2008).

Although model development with BRTs controls for overfitting (Friedman 2002), bivariate correlations were assessed and where variables showed a Spearman's rank correlation coefficient higher than 0.7 , only the variable considered to be ecologically more meaningful was retained. In a second variable selection step we tested univariate generalized linear models for all predictor variables using the GLM function in $\mathrm{R}(\mathrm{R}$ Development Core Team 2011). For variables potentially showing unimodal responses, such as canopy cover, the squared term of the predictor variable was also analyzed. Only significant variables $(P \leq 0.05$, Online Resource 4$)$ were further investigated. Although not necessary for fitting BRT models, this second explorative step provided insight into the individual explanation potential of each variable. 


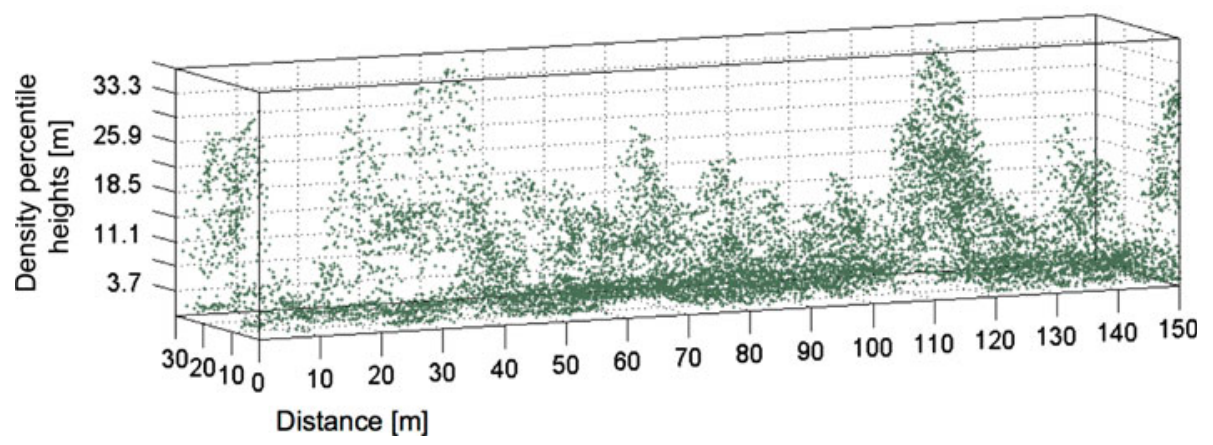

Fig. 3 An extract of a multi-layer raster of terrain corrected vegetation point heights. The $x$ - and $y$-axis form a raster grid with a resolution of $10 \mathrm{~m}$, whereby the $z$-axis is split into ten layers. In this case, the layer heights are the density percentiles with a fixed height distribution from the 10 th percentile $(3.7 \mathrm{~m})$ to the 100th percentile $(37 \mathrm{~m})$

For the remaining variables of each variable set (i.e. field, LiDAR and combined) we fitted BRT models in R using the dismo package (Hijmans et al. 2011) and custom written code provided by Elith et al. (2008). The optimal settings for the model parameters (number of trees, learning rate and tree complexity) were identified by comparing model performance for a wide range of different parameter combinations. Eventually, the three most parsimonious final models were identified by the simplification procedure proposed by Elith et al. (2008), which involves sequential removal of least important predictor variables based on cross-validation.

The relative importance of each predictor variable was determined based on how often a variable was selected and on the model improvement as a result of the selections (Elith et al. 2008). We estimated variable thresholds based on partial dependence plots, which show the effect of each habitat variable on the response variable. The fitted functions in the plots show the relative importance of a particular variable after taking into account the average effect of all other variables in the model (Hastie et al. 2001). Areas of distinctive increases or decreases of the fitted function thus indicate variable thresholds. However, threshold selection was based on visual interpretation and remains an estimation. Variable interactions were automatically identified by the modeling algorithm (Elith et al. 2008) but an inspection of the interaction sizes revealed only weak interactions, so we did not further consider them. The residuals of each final model were checked for spatial independence by calculating correlograms and Moran's I coefficients over various lag distances (Online Resource 5) (Quinn and Keough 2002) and no statistically significant spatial autocorrelation was found.

Model accuracy was determined by calculating two evaluation measures: the percentage of explained deviance $\left(\mathrm{D}^{2}\right)$ and the area under the receiver operating characteristic curve (AUC, Fielding and Bell 1997), for assessing both the model fit and the predictive performance based on ten-fold cross-validation. The AUC value is a threshold-independent measure that indicates the model's ability to discriminate between presence and absence and allows for a performance comparison between models (Fielding and Bell 1997). The interpretation scheme proposed by Hosmer and Lemeshow (2000) states that an AUC value of $0.7-0.8$ can be regarded as an acceptable model performance, $0.8-0.9$ is excellent and higher than 0.9 is considered outstanding. A value of 0.5 corresponds to a discrimination ability attained by chance. 


\section{Results}

Model performance

Both the field and the LiDAR model fitted excellently, and the combined model achieved an outstanding fit $\left(\mathrm{D}^{2}=56.5 \%\right.$, AUC $\left.=0.98\right)$. The predictive power, as determined by the mean explained deviance obtained from ten-fold cross-validation, ranged from 17.2 to $23.9 \%$ for the three models (i.e. field, LiDAR and combined), with mean AUC values of 0.77-0.81 (Table 1). All indices for model fit and predictive performance were significantly better for the combined model $(P<0.05$, Kruksal-Wallis and $t$ Tests).

Variable contribution and correlation

The most influential variable was the LiDAR-based CHH. It explained $44.2 \%$ of the deviance in the LiDAR model and contributed substantially $(19.5 \%)$ to the combined model (Table 2). Other important LiDAR variables included the clumpy index of patches with vegetation heights $>15 \mathrm{~m}$ (Clumpy_4) and the SDs in the 1st and 8th height and 4th density percentiles. Horizontal forest structures captured with FRAGSTATS explained $65.8 \%$ of the total explained deviance in the LiDAR and $34.1 \%$ in the combined model, whereas variables describing the vertical forest structure derived from point cloud statistics explained $34.2 \%$ in the LiDAR and $6.5 \%$ in the combined model.

Field variables related to the ground vegetation such as the overall cover, its distribution and composition with regard to bilberry and fern cover explained almost half of the deviance in the field model and about a third in the combined model. The availability of resource plants in the form of shrubs or trees such as tall rowans $(>3 \mathrm{~m})$ were further identified as important habitat elements. The number of basal branched trees, the only field-based forest structural variable retained by the field model, accounted for $19.5 \%$ explained deviance in the field model, however, contributed relatively little $(7.8 \%)$ to the combined model.

Field variables accounted for $59.4 \%$ of the combined model's performance, while LiDAR variables accounted for the remaining $40.6 \%$. Variables derived from LiDAR data using FRAGSTATS accounted for most of this contribution.

The two most important LiDAR variables, i.e. CHH and clumpy index clumpy index for CHM class 4, correlated significantly with the most important field variables, with correlation coefficients of up to $-0.61(P<0.001)$. In general, field variables related to the ground vegetation and the number of basal branched trees showed the highest correlations with LiDAR variables (Table 3).

\section{Variable thresholds}

The most influential variable $(\mathrm{CHH})$ had a positive effect on the occurrence of hazel grouse with a distinct threshold value of 40,000 m border length between canopy height classes per $\mathrm{km}^{2}$. However, more heterogeneous canopy heights did not further increase the probability of hazel grouse presence (Fig. 4). A proportion of resource trees of 10-40\% in the shrub layer gradually increased the habitat quality, as indicated by species occurrence. Apart from the ground vegetation cover, which showed a distinctive positive effect above a threshold of $50 \%$, all variables related to the ground vegetation were characterized by a gradual increase of the fitted functions. Index values above 0.75 for clumped vegetation 
Table 1 Performance of boosted regression trees, modeling hazel grouse presence/absence as a function of field and LiDAR-based variables and a combination thereof

\begin{tabular}{lccllllll}
\hline Model & D $^{2}$ & AUC & CV D $^{2}(\mathrm{SD})$ & CV AUC (SD) & No. variables & nt & lr & tc \\
\hline Field & 35.9 & 0.89 & $20.2(1.6)$ & $0.79(0.05)$ & 6 & 1,750 & 0.003 & 1 \\
LiDAR & 32.7 & 0.88 & $17.2(1.3)$ & $0.77(0.04)$ & 9 & 1,840 & 0.003 & 1 \\
Combined & 56.5 & 0.98 & $23.9(1.4)$ & $0.81(0.03)$ & 11 & 5,370 & $<0.001$ & 4 \\
\hline
\end{tabular}

The explained deviance $\left(\mathrm{D}^{2}\right)$ and the area under the receiver operating characteristics curve (AUC) obtained on the training data and the predictive performance and standard deviation obtained with ten-fold crossvalidation $\left(\mathrm{CV} \mathrm{D}^{2}(\mathrm{SD}), \mathrm{CV}\right.$ AUC $\left.(\mathrm{SD})\right)$ is shown. Beside the number of retained variables, the optimal parameter settings, i.e. the number of fitted trees (nt), the learning rate (lr) and tree complexity (tc) are provided with figures representing the mean of ten repeated runs with a bag fraction of 0.75

Table 2 Contribution of the predictor variables to the total deviance explained in the field, LiDAR and combined BRT model

\begin{tabular}{|c|c|c|c|}
\hline \multirow[t]{2}{*}{ Type of variable (bold) and variable name } & \multicolumn{3}{|c|}{ Contribution to model in $\%$} \\
\hline & Field & LiDAR & Combined \\
\hline \multicolumn{4}{|l|}{ Field variables } \\
\hline Ground vegetation cover & 20.1 & & 10.6 \\
\hline Basal branched trees & 19.6 & & 7.8 \\
\hline Total rowans $\geq 3 \mathrm{~m}$ & 17.4 & & 7.3 \\
\hline Ground vegetation distribution & 16.1 & & 6.6 \\
\hline Resource trees in shrub layer & 15.6 & & 11.5 \\
\hline Bilberry cover & 11.2 & & 8.2 \\
\hline Fern cover & & & 7.4 \\
\hline Total & 100 & & 59.4 \\
\hline \multicolumn{4}{|l|}{ LiDAR variables-FRAGSTATS } \\
\hline Canopy height heterogeneity $(\mathrm{CHH})$ & & 44.2 & 19.5 \\
\hline Clumpy index for CHM class 4 (Clumpy_4) & & 15.6 & 8.8 \\
\hline Shannon's diversity index for CHM class 1 and 2 & & 3.1 & 5.8 \\
\hline Shannon's diversity index for CHM class 2 and 3 & & 2.9 & \\
\hline Total & & 65.8 & 34.1 \\
\hline \multicolumn{4}{|l|}{ LiDAR variables-point cloud statistics } \\
\hline SD 40th density percentile & & 12.4 & \\
\hline SD 80th height percentile & & 9.3 & 6.5 \\
\hline SD 10th height percentile & & 8.3 & \\
\hline Mean 70th density percentile & & 3.1 & \\
\hline Mean 20th density percentile & & 1.1 & \\
\hline Total & & 34.2 & 6.5 \\
\hline
\end{tabular}

Canopy height model (CHM) classes as indicated in Fig. 2

heights above $15 \mathrm{~m}$ (Clumpy_4) showed a declining function and therefore decreased the habitat quality. The total number of basal branched trees and tall rowans, both being fieldbased count variables, showed a threshold effect at low values, suggesting the importance of these habitat elements being present in hazel grouse territories. 


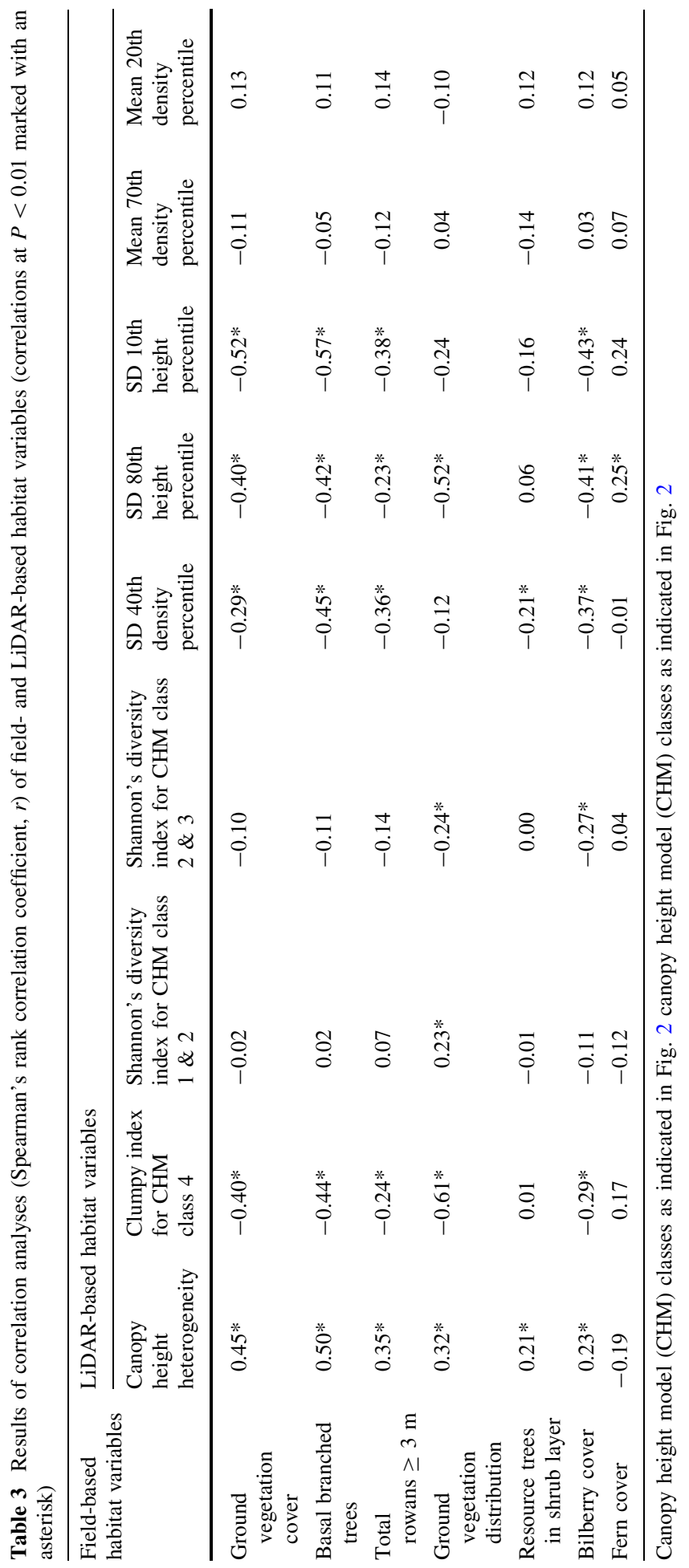




\section{Discussion}

We evaluated the capacity of LiDAR as a complementary source of information in habitat models, comparing field and LiDAR-based predictors across a wide range of mountain forest conditions. In line with previous studies which used LiDAR as a complimentary source of habitat information (e.g. Wilsey et al. 2012; Vierling et al. 2011), our LiDARand field-based habitat variables complemented each other well in a combined model; while the two separate variable sets produced models of similar, but lower accuracy. This finding, together with the characteristics of the retained variables substantiates the hypothesis that large scale, habitat relevant forest structural attributes cannot sufficiently be quantified by on-ground surveys. LiDAR proved to be a valuable alternative in overcoming this limitation by providing means of quantifying habitat relevant horizontal and vertical forest structures area-wide. Although significantly different from each other, the predictive performance of the three models suggests an applicability of all the three approaches as predictive tools, with the LiDAR-based approach being by far the most cost-effective (see also Müller and Brandl 2009; Müller et al. 2009b).

\section{LiDAR versus field variables}

LiDAR derived canopy heights and their variability have been shown to be useful in bird habitat assessments at local forest stand scales (Flaspohler et al. 2010; Vierling et al. 2008). Our study demonstrates that canopy height and its variability is also import at the regional, stand-mosaic scale, with $\mathrm{CHH}$ being a particularly strong indicator of suitable habitat. Forest stands with varying canopy heights are characterized by alternating light conditions in the understory and field layer, which in turn promotes the development of well known hazel grouse habitat elements such as rich ground vegetation, basal branched trees, and light demanding resource trees and shrubs (e.g. Schäublin and Bollmann 2011; Aberg et al. 2003). Although it has previously been argued that LiDAR-based measures of the forest vegetation's physiognomy were better predictors for bird assemblages than forest composition (Müller et al. 2010), our field-based model revealed a strong influence of individual, non-dominant resource trees and sub-canopy elements such as resource bushes and ground vegetation on the model's predictive performance. These habitat features can currently not be directly identified through LiDAR, nor with other remotely sensed data, despite progress in quantifying woody species composition based on optical imagery (Waser et al. 2011). However, a major advantage of LiDAR is that by reflecting differing light conditions, it can provide proxies for compositional and structural characteristics in the understory and the field layer (see also Simonson et al. 2012).

Hazel grouse is a distinctive food specialist depending on the resources provided by pioneer plant communities in early forest successional stages (Bergmann et al. 1996). During recent decades, graded transition zones from forest to open land have spread in mountain regions across the Alps, mainly due to farmland being left unmanaged and subsequent ingrowth (Gehrig-Fasel et al. 2007). These transitions are characterized by patchy occurrence of deciduous pioneer shrubs and tree regeneration, providing a smallscale mosaic of foraging opportunities and sufficient cover. The classified CHM reflects such transitions by varying canopy heights over small distances (Fig. 5), resulting in heterogeneous canopy height profiles. Further, our study design and methods allowed for deriving novel variables of forest patch configuration. Such variables include the clumpy index of canopy heights above $15 \mathrm{~m}$, where high values indicate the dominance of structurally poor, mostly single layered forest patches with a sparsely developed or missing 

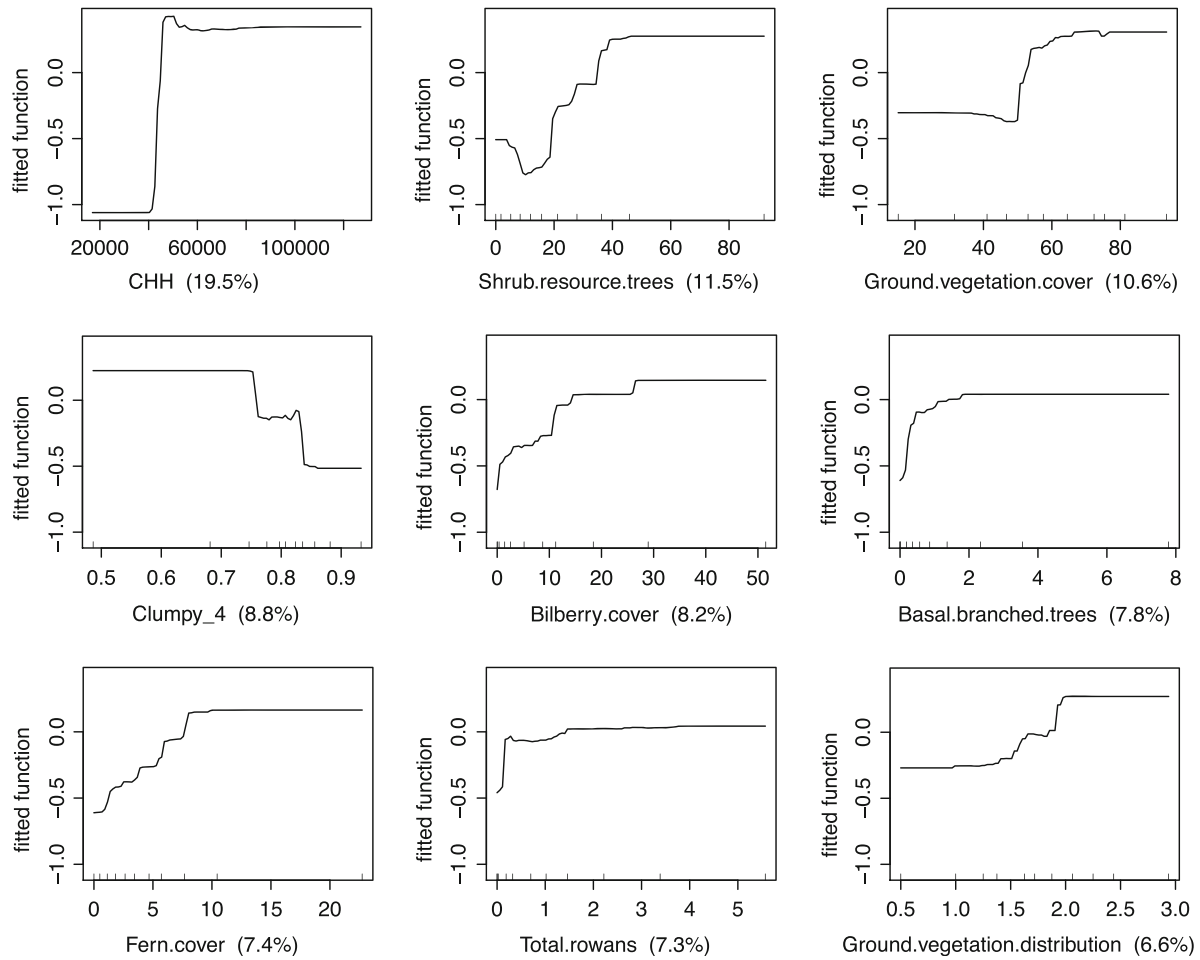

Fig. 4 Partial dependence plots for the nine most influential variables retained by the combined BRT model. The graphs show the effect of a particular variable (for entities see Online Resource 1): increasing fitted function values indicate that hazel grouse presence/absence responded positively, decreasing values the opposite. Values on the $y$-axis are uniformly scaled so that the relative importance of the variables can be visually compared (Hastie, Tibshirani and Friedman 2001). The relative contribution of each variable to the total deviance explained is shown in parentheses

understory. Hazel grouse avoid such stands if they extend over large areas, because they provide neither sufficient cover nor resources (Müller et al. 2009a). Similarly, our results indicate that hazel grouse favor areas with a small variance within the vertical forest structure. Initially, this seems counterintuitive because a high SD within the vertical foliage profile could be interpreted as structural richness and therefore positive for hazel grouse. But since the SD was calculated between all $10 \times 10 \mathrm{~m}$ boxes of a particular percentile layer (Fig. 3), smaller values reflect a more evenly distributed, multi-layered vertical forest structure, in contrast to a vertical profile that is dominated by a single or two layered structure resulting in high SDs of heights between the boxes (Zellweger et al. 2013).

Analysis of scale and model performance

The scale in habitat assessments should match the home range or territory size associated with the species of interest, which is about 20-40 ha in the case of hazel grouse (Swenson 1991). Thus, most previous hazel grouse studies (e.g. Müller et al. 2009a; Schäublin and Bollmann 2011) as well as LiDAR-based assessments of species-habitat relationships (e.g. Goetz et al. 2010; Swatantran et al. 2012) have worked with higher than $1-\mathrm{km}^{2}$ resolutions in species data. However, the limited availability of highly resolved species data and 


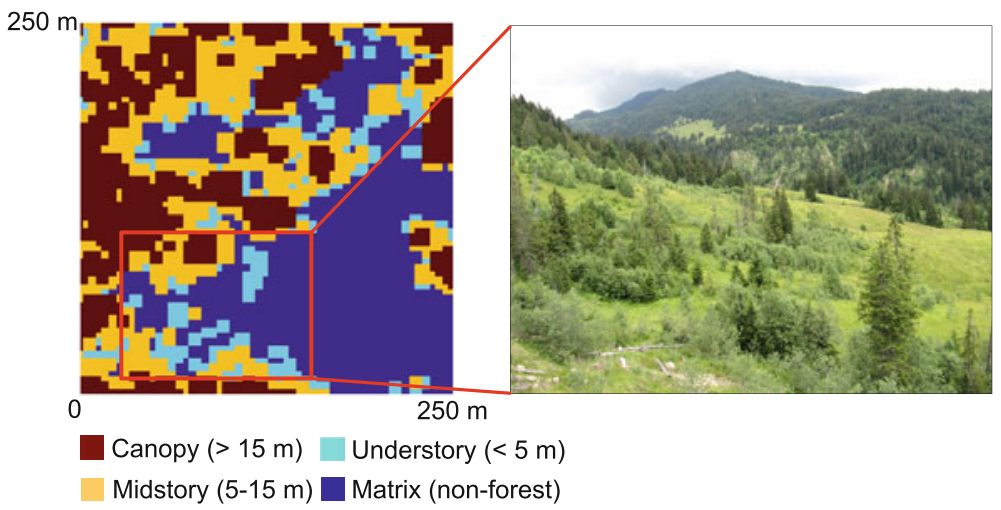

Fig. 5 Extract of classified canopy height model (CHM) with a pixel size of $4 \mathrm{~m}$ showing continuous transitions from forest to open land due to ingrowth (abandonment of farming) (left). The transition zone within the red square is characterized by a patchy occurrence of deciduous pioneer woods, spruce regeneration and alpine meadows (right)

related logistical costs normally restrict the spatial extent of such studies (Braunisch and Suchant 2010). Our approach involves area-wide species data distributed across Switzerland, which allowed us to cover a wide range of habitats and thus an extensive number of the species realized ecological niches. This representativeness has been shown to be preferable for improving the generality of model predictions under the described trade-off conditions (Graf et al. 2006), even when it comes at the cost of a coarser grain size (Braunisch and Suchant 2010), as in our study. In contrast to the previous studies, our design was targeted at assessing the environmental mosaic under the expectation thatgiven the species' association with dynamic patterns of pioneer stages-not only the conditions within the territory itself, but within the surrounding forest landscape play a crucial role for long-term species occurrence. Nevertheless, uncertainty with regard to the precise location of species evidence (i.e. whether the observations allocated to the corresponding $1 \mathrm{~km}^{2}$ were located centrally or at border of the cell) may have introduced a considerable amount of variability in habitat quality to presence cells, which itself could have reduced cross-validation accuracy. A similar effect resulting from grain size on modeling results was discovered in other LiDAR-based bird habitat models (Wilsey et al. 2012). However, in spite of the coarse scale, the goodness of fit of our models was in the range of a number of LiDAR-based habitat models with finer grain sizes (Graf et al. 2009; Müller et al. 2009b; Lesak et al. 2011). This underlines the high ecological relevance of variables operating at larger scales, and the importance of LiDAR for capturing forest habitat patch-configuration rather than stand-scale structure. Promising results from studies that combined LiDAR with other remote sensing data suggest that our LiDAR model could probably be further improved by incorporating data from aerial photographs and multispectral data, such as the normalized difference vegetation index (NDVI) (Goetz et al. 2007; Müller et al. 2009b; Zellweger et al. 2013).

The selection of pseudo-absence cells may also have lowered the models' accuracy. Our pseudo-absence cells were selected based on the fact that hazel grouse were not reported for these cells in the eleven years between 2000 and 2010. Based on this extended period of missing evidence, we expected to minimize the potential bias in the species absence data that could originate from varying survey efforts or from lack of detections due to reasons other than suboptimal habitat characteristics, such as survey season or time of the day 
(MacKenzie et al. 2002). Nevertheless, hazel grouse was confirmed in some of the putative absence cells during the field work. Together with ingrowth of alpine pastures, the forest dynamics following severe windstorms in 1990 and 1999 (Schönenberger 2002) have likely resulted in an expansion of the hazel grouse distribution during recent years. Our sampling strategy thus may represent a rather conservative estimate of the current distribution of hazel grouse. By reclassifying an absence cell as a presence cell, if direct and/or indirect evidence of hazel grouse presence was recorded, we partially accounted for this development.

\section{Application}

Our approach entails two benefits. First, it bridges the gap between different ecologically relevant scales, such as habitat configuration and structure at the scales related to second and third order habitat selection (Johnson 1980). Second, the broad spatial coverage of our LiDAR data and the reference area of $1 \mathrm{~km}^{2}$ correspond well with the requirements of forest management aiming at integrating local conservation efforts into regional forest planning. For example, large-scale mapping of habitat structure allows for the detection of areas with particularly suitable habitat and can inform management where to allocate resources most efficiently to improve habitat connectivity.

To make concise recommendations to forest managers it is desirable to derive distinctive indicators that can be translated into operational measures for forestry and habitat management. Thresholds derived from species-habitat analysis support the development of applicable indicators. Field variables often meet the requirement of applicability. However, an explicit practical translation of the LiDAR variable $\mathrm{CHH}$ remains difficult because of the variable's technical background. While the difficulty in translating LiDAR variables into applicable measures currently limits the practical use and calls for further development, an integrative interpretation across all LiDAR variables still allows for management recommendations, such as selective group cutting to promote multistoried and structurally rich forests.

\section{Conclusions}

LiDAR is a powerful and cost-effective tool to quantify structure-dependent specieshabitat relationships at the landscape scale. By providing detailed three-dimensional data of canopy structure, LiDAR-based habitat variables represent important characteristics related to the composition and structure of the understory and ground vegetation. This allows for an improved integration of conservation targets into both regional and local forest planning and management, since forest inventories can be amended by conservationrelevant information about the configuration, distribution and connectivity of habitat patches. LiDAR offers the possibility to bridge the gap between the currently prevailing, broad scale habitat models based on conventional GIS and remote sensing techniques and resource selection models at local scales, thus being beneficial for conservation programs aiming at regional population persistence. Further, multi-temporal LiDAR data acquisition or photogrammetric updates of the canopy height model would allow for tracking forest dynamics and for surveying conservation related management practices and their impacts. Given the high level of detail and large extent of available data, the wide array of LiDAR derived measures of forest structures offer new possibilities to develop and evaluate indicators of forest biodiversity at various scales. 
Acknowledgments This study was part of a research project funded by the research programme 'Forest and climate change' of the Swiss Federal Inst. for Forest, Snow and Landscape Research WSL and the Federal Office for the Environment FOEN. We are grateful to the Swiss Ornithological Institute for providing the species data. Special thanks to all the people involved in the field work, namely Lisa Bitterlin, Lucretia Deplazes, Nino Maag, Lea Hofstetter, Maria Rusche, Karin Feller and Joy Coppes.

\section{References}

Aberg J, Swenson JE, Angelstam P (2003) The habitat requirements of hazel grouse (Bonasa bonasia) in managed boreal forest and applicability of forest stand descriptions as a tool to identify suitable patches. For Ecol Manag 175(1-3):437-444

Artuso R, Boyet S, Streilein A (2003) Practical methods for the verification of countrywide terrain and surface models. Int Arch Photogramm Remote Sens 34:1419

Attiwill PM (1994) The disturbance of forest ecosystems: the ecological basis for conservative management. For Ecol Manag 63(2-3):247-300

Bergmann H-H, Klaus S, Müller F, Scherzinger W, Swenson JE, Wiesner J (1996) Die Haselhühner-4. überarbeitete Auflage. Die neue Brehm-Bücherei Bd.77. Westarp Wissenschaften, Magdeburg

Bradbury RB, Hill RA, Mason DC, Hinsley SA, Wilson JD, Balzter H, Anderson GQA, Whittingham MJ, Davenport IJ, Bellamy PE (2005) Modelling relationships between birds and vegetation structure using airborne LiDAR data: a review with case studies from agricultural and woodland environments. Ibis 147(3):443-452

Braunisch V, Suchant R (2010) Predicting species distributions based on incomplete survey data: the tradeoff between precision and scale. Ecography 33(5):826-840

Clawges RM, Vierling KT, Vierling LA, Rowell E (2008) The use of airborne lidar to assess avian species diversity, density, and occurrence in a pine/aspen forest. Remote Sens Environ 112(5):2064-2073

Elith J, Leathwick JR, Hastie T (2008) A working guide to boosted regression trees. J Anim Ecol 77(4):802-813

Fielding AH, Bell JF (1997) A review of methods for the assessment of prediction errors in conservation presence/absence models. Environ Conserv 24(1):38-49

Flaspohler DJ, Giardina CP, Asner GP, Hart P, Price J, Lyons CKA, Castaneda X (2010) Long-term effects of fragmentation and fragment properties on bird species richness in Hawaiian forests. Biol Conserv 143(2):280-288

Franklin JF, Spies TA, Van Pelt R, Carey AB, Thornburgh DA, Berg DR, Lindenmayer DB, Harmon ME, Keeton WS, Shaw DC, Bible K, Chen JQ (2002) Disturbances and structural development of natural forest ecosystems with silvicultural implications, using Douglas-fir forests as an example. For Ecol Manag 155(1-3):399-423

Friedman JH (2002) Stochastic gradient boosting. Comput Stat Data Anal 38(4):367-378

Gehrig-Fasel J, Guisan A, Zimmermann NE (2007) Tree line shifts in the Swiss Alps: climate change or land abandonment? J Veg Sci 18(4):571-582

Goetz SJ, Steinberg D, Dubayah RO, Blair B (2007) Laser remote sensing of canopy habitat heterogeneity as a predictor of bird species richness in an eastern temperate forest, USA. Remote Sens Environ 108(3):254-263

Goetz SJ, Steinberg D, Betts MG, Holmes RT, Doran PJ, Dubayah R, Hofton M (2010) Lidar remote sensing variables predict breeding habitat of a Neotropical migrant bird. Ecology 91(6):1569-1576

Gonseth Y, Wohlgemuth T, Sansonnens B, Buttler A (2001) Die biogeographischen Regionen der Schweiz. Erläuterungen und Einteilungsstandard. Umwelt Materialien Nr. 137 Bundesamt für Umwelt, Wald und Landschaft, Bern

Goodwin NR, Coops NC, Bater CW, Gergel SE (2007) Assessment of sub-canopy structure in a complex coniferous forest. In: Proceedings of the ISPR Workshop "Laser Scanning 2007 and SilviLaser 2007", Espoo, September 12-14, 2007, Finland, vol XXXVI ISSN:1682-1777, P3/W52:169-172

Graf RF, Bollmann K, Sachot S, Suter W, Bugmann H (2006) On the generality of habitat distribution models: a case study of capercaillie in three Swiss regions. Ecography 29(3):319-328

Graf RF, Mathys L, Bollmann K (2009) Habitat assessment for forest dwelling species using LiDAR remote sensing: Capercaillie in the Alps. For Ecol Manag 257(1):160-167

Hastie T, Tibshirani R, Friedman JH (2001) The elements of statistical learning: sata mining, inference, and prediction. Springer series in statisticsSpringer, New York 
Hijmans RJ, Phillips SJ, Leathwick JR, Elith J (2011) Species distribution modeling (dismo). Package version 0.7-8. http://cran.r-project.org/web/packages/dismo/index.html. Accessed 20 April 2012

Hill RA, Hinsley SA, Gaveau DLA, Bellamy PE (2004) Predicting habitat quality for Great Tits (Parus major) with airborne laser scanning data. Int J Remote Sens 25(22):4851-4855

Hosmer DW, Lemeshow S (2000) Applied logistic regression, 2nd edn. Wiley, New York

Johnson DH (1980) The comparison of usage and availability measurements for evaluating resource preference. Ecology 61(1):65-71

Jones J (2001) Habitat selection studies in avian ecology: a critical review. Auk 118(2):557-562

Keller M (2005) Schweizerisches Landesforstinventar. Anleitung für die Feldaufnahmen der Erhebung 2004-2007. Eidg. Forschungsanstalt WSL, Birmensdorf

Klaus S, Martens J, Andreev AV, Sun Y-H (2003) Bonasa bonasia (Linnaeus, 1758). Atlas Verbr Palaearkt Vögel 20:1-15

Larsson T-B (2001) Biodiversity evaluation tools for European forests. Ecol Bull 50:000

Lefsky MA, Cohen WB, Parker GG, Harding DJ (2002) Lidar remote sensing for ecosystem studies. Bioscience 52(1):19-30

Lesak AA, Radeloff VC, Hawbaker TJ, Pidgeon AM, Gobakken T, Contrucci K (2011) Modeling forest songbird species richness using LiDAR-derived measures of forest structure. Remote Sens Environ 115(11):2823-2835

Lindenmayer DB, Margules CR, Botkin DB (2000) Indicators of biodiversity for ecologically sustainable forest management. Conserv Biol 14(4):941-950

MacKenzie DI, Nichols JD, Gideon BL, Droege S, Royle JA, Langtimm CA (2002) Estimating site occupancy rates when detection probabilities are less than one. Ecology 83(8):2248-2255

Mathys L, Zimmermann NE, Zbinden N, Suter W (2006) Identifying habitat suitability for hazel grouse Bonasa bonasia at the landscape scale. Wildl Biol 12(4):357-366

McGarigal K, Cushman SA, Neel MC, Ene E (2002) FRAGSTATS: spatial pattern analysis program for categorical maps. Computer software program. University of Massachusetts, Amherst. http://www. umass.edu/landeco/research/fragstats/-fragstats.html. Accessed 15 Aug 2012

Morsdorf F, Marell A, Koetz B, Cassagne N, Pimont F, Rigolot E, Allgöwer B (2010) Discrimination of vegetation strata in a multi-layered Mediterranean forest ecosystem using height and intensity information derived from airborne laser scanning. Remote Sens Environ 114(7):1403-1415

Müller J, Brandl R (2009) Assessing biodiversity by remote sensing in mountainous terrain: the potential of LiDAR to predict forest beetle assemblages. J Appl Ecol 46(4):897-905

Müller D, Schroder B, Müller J (2009a) Modelling habitat selection of the cryptic Hazel Grouse Bonasa bonasia in a montane forest. J Ornithol 150(4):717-732

Müller J, Moning C, Bässler C, Heurich M, Brandl R (2009b) Using airborne laser scanning to model potential abundance and assemblages of forest passerines. Basic Appl Ecol 10(7):671-681

Müller J, Stadler J, Brandl R (2010) Composition versus physiognomy of vegetation as predictors of bird assemblages: the role of lidar. Remote Sens Environ 114(3):490-495

Noss RF (1990) Indicators for monitoring biodiversity - a hierarchical approach. Conserv Biol 4(4):355-364

Quinn GP, Keough MJ (2002) Experimental design and data analysis for biologists. Cambridge University Press, Cambridge

R Development Core Team (2011) R: a language and environment for statistical computing. Package version 2.13.2. R Foundation for Statistical Computing, Vienna

Schäublin S, Bollmann K (2011) Winter habitat selection and conservation of Hazel Grouse (Bonasa bonasia) in mountain forests. J Ornithol 152(1):179-192. doi:10.1007/s10336-010-0563-3

Schönenberger W (2001) Trends in mountain forest management in Switzerland. Schweizerische Zeitschrift für Forstwesen 152:152-156

Schönenberger W (2002) Windthrow research after the 1990 storm Vivian in Switzerland: objectives, study sites, and projects. For Snow Landsc Res 77(1-2):9-16

Seavy NE, Viers JH, Wood JK (2009) Riparian bird response to vegetation structure: a multiscale analysis using LiDAR measurements of canopy height. Ecol Appl 19(7):1848-1857

Simonson WD, Allen HD, Coomes DA (2012) Use of an airborne lidar system to model plant species composition and diversity of Mediterranean oak forests. Conserv Biol 26(5):840-850

Stöcklin J, Bosshard A, Klaus G, Rudmann-Maurer K, Fischer M (2007) Landnutzung und biologische Vielfalt in den Alpen - Thematische Synthese zum Forschungsschwerpunkt 2 "Land- und Forstwirtschaft im alpinen Lebensraum" des Nationalen Forschungungsprogramms NFP 48 "Landschaften und Lebensräume der Alpen" des Schweizerischen Nationalfonds SNF. vdf Hochschulverlag AG, Zürich

Swatantran A, Dubayah R, Goetz SJ, Hofton M, Betts MG, Sun M, Simard M, Holmes R (2012) Mapping migratory bird prevalence using remote sensing data fusion. PLoS One 7(1):e28922 
Swenson JE (1991) Social organization of hazel grouse and ecological factors influencing it. Dissertation, University of Alberta, Edmonton, Canada

Swisstopo (2012) VECTOR25. http://www.swisstopo.admin.ch/internet/swisstopo/-de/home/products/ landscape/vector25.html. Accessed 13 Jan 2012

Turner W, Spector S, Gardiner N, Fladeland M, Sterling E, Steininger M (2003) Remote sensing for biodiversity science and conservation. Trends Ecol Evol 18(6):306-314

Vierling KT, Vierling LA, Gould WA, Martinuzzi S, Clawges RM (2008) Lidar: shedding new light on habitat characterization and modeling. Front Ecol Environ 6(2):90-98

Vierling KT, Bässler C, Brandl R, Vierling LA, Weiss I, Müller J (2011) Spinning a laser web: predicting spider distributions using LiDAR. Ecol Appl 21(2):577-588

Waser LT, Ginzler C, Kuechler M, Baltsavias E, Hurni L (2011) Semi-automatic classification of tree species in different forest ecosystems by spectral and geometric variables derived from airborne digital sensor (ADS40) and RC30 data. Remote Sens Environ 115(1):76-85

Wilsey CB, Lawler JJ, Cimprich DA (2012) Performance of habitat suitability models for the endangered black-capped vireo built with remotely-sensed data. Remote Sens Environ 119:35-42

Zellweger F, Braunisch V, Baltensweiler A, Bollmann K (2013) Remotely sensed forest structural complexity predicts multi species occurrence at the landscape scale. For Ecol Manag 307:303-312 